\title{
Electromechanical Surfacing Technique
}

\author{
Alla Gerasimova ${ }^{1, a^{*}}$, Alexey Karfidov ${ }^{1, b}$, Boris Belelybskii ${ }^{2, c}$ and \\ Kirill Goloshapov ${ }^{1, d}$ \\ ${ }^{1}$ National University of Science and Technology "MISIS", street the Lenin prospect,4, \\ Moscow,119049, Russia \\ ${ }^{2}$ Department of Mechanical Engineering, Moscow Polytechnical University, Bolshaya \\ Semyonovskaya str., 38, Russia \\ agerasimova.aa@misis.ru, ba.korf@mail.ru, cnis_mgvmi@mail.ru, dgoloshapov_nooby@mail.ru
}

\section{Keywords: Structure, Surface Layer, Part, Roller-Type Tools, Surface Treatment}

\begin{abstract}
The paper considers an electromechanical surfacing technique of parts' work surfaces. It was found out that depending on strain temperature, rate and degree there were special type structures formed on a surface layer with a phase change (a bright layer), i.e. a hot deformed structure with and without recrystallization and a cold deformed structure. Depending on the original structure and hardening conditions, during surfacing of parts a thickness of this area may achieve $0.3 \mathrm{~mm}$ max. Impact of steel electromechanical treatment on the structure and the surface layer was found out. Depending on properties of surfaces being treated it is possible to use platelike and roller-type tools for electromechanical hardening. It was shown that roller- type tools possessed enhanced durability and enlarged areas of surfaces being treated, though ensured poorer finish of surfaces being treated.
\end{abstract}

\section{Introduction}

Electromechanical surface hardening technique is based on a combination of thermal actions and forces applied to the surface layer of the part being treated. The essence of the technique is that in the course of part treatment, large current is passing under low voltage through the contact place of tools with the article; due to this fact protruding surface crests are subject to vigorous heating, are deformed under a pressure of tools and polished while the metal surface layer hardens [1-8].

Electromechanical surface hardening technique is used for hardening and reconditioning worn surfaces of parts. For example, this technique is utilized for reconditioning surfaces of antifriction bearings.

Electromechanical surface hardening technique process may be considered as a special type of metal surface thermomechanical treatment. High temperature thermomechanical treatment is one of thermomechanical treatment techniques. In this case depending on strain temperature, rate and degree there are special type structures formed on a surface layer with a phase change (a bright layer), i.e. a hot deformed structure with and without recrystallization and a cold deformed structure. Depending on the original structure and hardening conditions, during surfacing of rotary parts a thickness of this area may achieve $0.3 \mathrm{~mm}$ max. [9-16].

A bright strip was identified for the first time by V.P. Kravz-Tarnosky during impact tests of steel specimens. N.N. Davidenkov and I. N. Mirolubov explain Kravz-Tarnosky effect so that there is substance destruction and crushing along one shear area due to local deformation. With rapid sliding due to high friction, primarily large amounts of heat are generated which are transferred at high speed to the specimen basic mass and then to the steel anvil and hammer head. That's why at places of strain localization where the temperature is likely to exceed its limit level, there is primarily austenitic transformation and intense quenching further on. The layer substance has 
martensite texture with no specific needlelike structure since it has been formed under special conditions of overpressure and velocity of transformation that have not been explored yet [17-20].

Similar structures were found in surface layers of various machine parts. However, there is no consensus yet to the nature of this structure. Some persons attribute the formation of non-etching bright area to the saturation of friction surface with air nitrogen. Other persons consider the bright area to be a consequence of oxygen diffusion into the metal surface layer that results in formation of solid solutions and chemical compounds. The third ones conclude that the bright area structure consists of martensite, retained austenite and alloyed cementite. Differences of opinion about the nature of bright area formation are apparently explained by friction dissimilar conditions [21-24].

\section{Methods and materials}

Depending on impact on the surface layer structure and properties, the following electromechanical treatments are distinguished:

- thermal treatment when there is the bright area formed at a significant depth while there is no ductile deformation in the transition layer. This treatment features phase changes and complete rest;

- incomplete thermal treatment with homogeneous area viewed in the surface layer; the transition sub-layer is severely deformed and features partial rest viewed in the homogeneous surface layer.

Depending on properties of surfaces being treated it is possible to use plate-like and roller-type tools for electromechanical surface hardening technique.

A holder with plate-like carbide tip (refer with: Fig. 1) works well for electromechanical surface hardening technique of relatively small areas. Working surfaces of polishing plates should be adequately clean. That's why after pattern filling with a carborundum wheel they should be semifinished with boro-carbon on cast iron disk. A lapping compound should be made of boron carbide powder and wax at a ratio of 7: 3 . Due to lack of boron carbide some small enterprises provide smoothening plates with semi-finishing on common emery wheels.

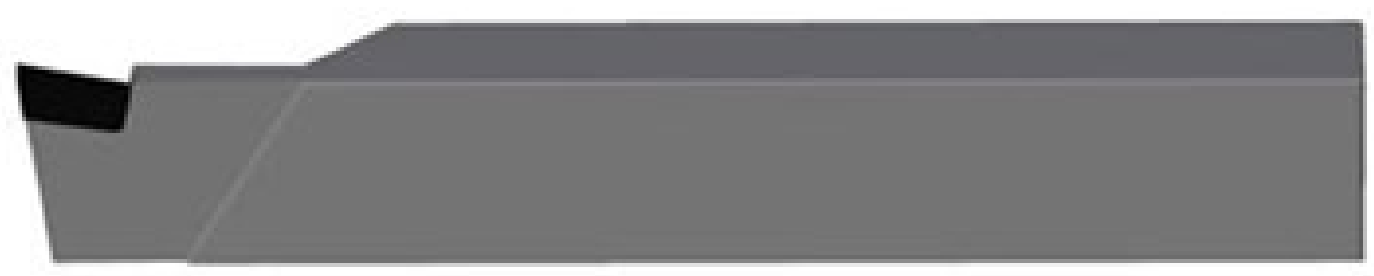

Fig. 1. Holder with plate-like tools

When processing large areas with the necessity for profound hardening under high current of 900-1,200 A the use of roller-type tools is more rational (refer with: Fig. 2). The roller-type holder is similar to the common holder of polishing tools. The roller made of carbide material should be installed on the axis and secured in the holder body with the help of retention screws. 


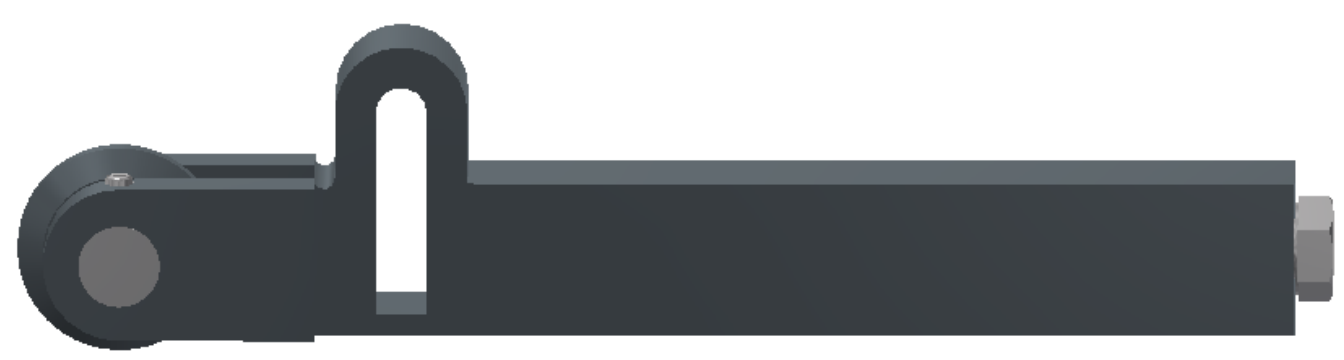

Fig. 2. Holder with roller-type tools

Test conducted on these tools demonstrated their high performance during continuous and long term operation under high current. However the surface finish obtained in this case somewhat poorer in comparison with its surfacing with the plate. It should be stated that holders (refer with: Fig.1, Fig.2) may be adapted for fixed mounting of carbide rollers if structurally changed a little bit. In this case the roller operates as the circular plate; while the best possibility for changing contact surfaces by means of periodic rotation of the roller, dozen times increases wear-resisting properties of these tools in comparison with the plate. Comparative analysis of roller-type and plate-like tools (refer with: Table 1).

Table 1. Comparison of properties of roller-type and plate-like tools [25]

\begin{tabular}{|l|c|c|}
\hline \multicolumn{1}{|c|}{ Parameters } & Plate-like tools & Roller-type tools \\
\hline Surfaces being treated & Relatively small & Very large \\
\hline Current mode, $[\mathrm{A}]$ & $300-800$ & $900-1,200$ \\
\hline Reduction in roughness & $2-3$ class & $1-2$ class \\
\hline $\begin{array}{l}\text { Wear-resisting properties } \\
\text { (treatment till the repeated semi- } \\
\text { finishing, }[\mathrm{mm}] \text { ) }\end{array}$ & $2,500-3,000$ & $>30,000$ \\
\hline
\end{tabular}

\section{Conclusions}

Summing up what has been said, roller-type tools possess enhanced durability and enlarged areas of surfaces being treated, however, they ensure poorer finish of surfaces being treated.

\section{References}

[1] V.V. Eltsov, Reconditioning and hardening machine parts, Togliatti, Togliatti State University (TGU), 2015.

[2] B.M. Askinazi, Hardening and reconditioning machine parts by electromechanical surfacing, Moscow, Mashinostroyenie, 1989.

[3] A. Keropyan, S. Gorbatyuk, Impact of Roughness of Interacting Surfaces of the Wheel-Rail Pair on the Coefficient of Friction in their Contact Area, Procedia Engineering. 150 (2016) 406410. https://doi.org/10.1016/j.proeng.2016.06.753

[4] A.G. Radyuk, S.M. Gorbatyuk, Y.S. Tarasov, A.E. Titlyanov, A.V. Aleksakhin, Improvements to mixing of natural gas and hot-air blast in the air tuyeres of blast furnaces with thermal isulation of the blast duct, Metallurgist. 63(5-6) (2019) 433-440. https://doi.org/10.1007/s11015-019-00843-6 
[5] L.V. Sedykh, S.V. Albul, D.B. Efremov, M.A. Sukhorukova Application of additive technologies for manufacturing a wear-resistant steel pipe outlet, IOP Conf. Series: Materials Science and Engineering. 971(2) (2020), 022002. https://doi.org/10.1088/1757899X/971/2/022002

[6] V.E. Kondratenko, V.V. Devyatiarova, S.V. Albul, D.S. Kartyshev, Improving methodology for calculating scaffolding formwork of monolithic slabs in building constructions, IOP Conf. Series: Materials Science and Engineering. 971(5) (2020), 052037. https://doi.org/10.1088/1757899X/971/5/052037

[7] V.V. Devyatiarova, E.E. Balakhnina, L.M. Valeeva, Development of a mathematical model for a workpiece heating and cooling in a protective medium while treatment under pressure, Defect $\begin{array}{lllll}\text { and } & \text { Diffusion } & \text { Forum. } & 410 & \text { (2021) }\end{array}$ https://doi.org/10.4028/www.scientific.net/DDF.410.115

[8] A.D. Bardovsky, L.M. Valeeva, I.I Basyrov, A plant with a rotary jet grinder to produce small fractions of mineral raw material, IOP Conf. Series: Materials Science and Engineering. 971 (2020), 052004. https://doi.org/10.1088/1757-899X/971/5/052004

[9] O.E. Markov, V.V. Kukhar, V.N. Zlygoriev, A.A. Shapoval, A.S. Khvashchynskyi, R.U. Zhytnikov, Improvement of upsetting process of four-beam workpieces based on computerized and physical modeling, FME Transactions. 48(4) (2020) 946-953. https://doi.org/10.5937/fme2004946M

[10] A.A. Fomin, V.G. Gusev, Spindle rigidity in milling blanks with nonuniform properties, Russian Engineering Research. 33(11) 646-648. https://doi.org/10.3103/S1068798X13110087

[11] S.A. Snitko, A.V. Yakovchenko, V.V. Pilipenko, N.I. Ivleva, Modeling of ring billets rolling on radial-axial ring-rolling mill, Izvestiya Ferrous Metallurgy. 63(8) (2020) 665-673. https://doi.org/10.17073/0368-0797-2020-8-665-673

[12] A.A. Fomin, Determining undeformed chip thickness models in milling and its verification during wood processing, Solid State Phenomena. 265 (2017) 598-605. https://doi.org/10.4028/www.scientific.net/SSP.265.598

[13] V. Artiukh, V. Mazur, L. Shilova, Device for making horizontal wedgethrust of rolling stand, $\begin{array}{llllll}\text { MATEC Web } & \text { of } & \text { Conferences. } & 106 & \text { (2017), } & 03002 .\end{array}$ https://doi.org/10.1051/matecconf/201710603002

[14] V. Artiukh, V. Kukhar, E. Balalayeva, Refinement issue of displaced volume at upsetting of cylindrical workpiece by radial dies, MATEC Web of Conferences. 224 (2018), 01036. https://doi.org/10.1051/matecconf/201822401036

[15] A.O. Karfidova, M.V. Vasilyev, I.G. Morozova, Modernization of an industrial passive exoskeleton prototype for lower extremities using rapid prototyping technologies, IOP Conf. Ser.: Mater. Sci. Eng. 971 (5) (2020), 052049. https://doi.org/10.1088/1757-899X/971/5/052049

[16] S.M. Gorbatyuk, A.A. Gerasimova, A.G. Radyuk, Using the coating for the diffusion layer OBTAINING on the walls of the mold (CCM), Metallurgical and Mining Industry. 7 (9) (2015) 1085-1088. 
[17] A.Y. Albagachiev, A.M. Keropyan, A.A. Gerasimova, O.A. Kobelev, Determination of rational friction temperature in lengthwise rolling, CIS Iron and Steel Review. 19 (2020) 33-36. https://doi.org/10.17580/cisisr.2020.01.07

[18] A.M. Busygin, Self-adjusting differential rotary feeding system of the drilling rig, IOP Conf. Ser.: Mater. Sci. Eng. 971(4) (2020), 042099. https://doi.org/10.1088/1757-899X/971/4/042099

[19] A. Bardovsky, I. Basyrov, L. Valeeva, Systematization of the mineral raw material waste recycling process, MATEC Web of Conferences. $346 \quad$ (2021), 03040. https://doi.org/10.1051/matecconf/202134603040

[20] V.N. Titov, A.I. Ternovikh, P.V. Baranov, T.Y. Sidorova, Development of coatings for protection of blast furnace air tuyeres, Metallurgist. 65 (3-4) (2021) 439-445. https://doi.org/10.1007/s11015-021-01174-1

[21] O.A. Kobelev, V.A. Tyurin, Production of large plates, Steel in Translation. 37(9) (2007) 727-729. https://doi.org/10.3103/S096709120709001X

[22] K.N. Solomonov, L.I. Tishchuk, Simulation of deformation processes in upsetting, Journal of Physics: Conf. Series. 1348 (1) (2019), 012020. https://doi.org/10.1088/17426596/1348/1/012020

[23] S.V. Bashkin, A.O. Karfidov, V.N. Kornienko, et al., An imaging Fourier transform spectroradiometer with a multi-element photodetector for the spectral range of 7-14 $\mu \mathrm{m}$, Optics and Spectroscopy. 121(3) (2016) 449 - 454. https://doi.org/10.1134/S0030400X16090058

[24] L.R. Lamberson, K.S. Kapur, Reliability in engineering design, Weliy India Pvt. Limited, 2009.

[25] Elektromekhanicheskaya-obrabotka. URL: http://www. stroy-technics.ru (date: 01.08.21) 